\title{
EATING HISTORY: A UNITED STATES HISTORY PROJECT
}

\author{
Christopher Lewis \\ Chapman University
}

Our lives are enlivened by sensory experience. Memories are constructed with the building blocks of what we see, touch, taste, smell, and hear. Learning occurs best when our minds and bodies are engaged actively and challenged by new experiences and situations. Teaching history allows me to explore the various ways students learn: analyzing visual and music sources, engaging in total physical response, and also reflecting to build empathy and problem-solving skills. However, it was not until recently that I realized one sense is often ignored in teaching: the sense of taste. Taste might be one of the strongest and most engaged in our lives. We all eat. What we eat reflects our personal and social situation. But the use of food as a teaching tool is not limited to the sense of taste. Food engages all of our senses. And thus, I argue that thinking historically is not limited to what we read or discuss. Studying history must include an exploration of what we eat as well.

History classes are frequently difficult for students because they fail to make connections between the past, the present, and the future. Therefore, students struggle with practicing periodization, identifying cause and effect, or analyzing primary source documents that reflect the political, social, and economic tensions of any given time period. Teachers use photographs, political cartoons, or personal narratives to incite discussion and develop critical thinking about the past. But these materials might create distance between students and studying history where history is to be acquired or obtained instead of lived. Students do not see themselves as participants actively creating, making, and navigating their own personal histories. Thus, history is reduced to memorizing names, events, and dates about people that are not connected to students' immediate experiences. History educators bear a responsibility that is unlike many other subjects. The way in which history is presented can positively or negatively affect a student's self-efficacy, identity development, and worldview.

We might narrow the distance between past and present by using food as a tool for historical analysis. By studying history from a thematic perspective with food and food ephemera as the centerpieces, we can explore issues of immigration, migration, assimilation, and identity development more creatively. Food is an element of survival and all humans share it as an experience that relates to the development of cultural identity. Where our food comes from, what we eat, and how it is prepared, all become part of our cultural performance. For many immigrants, food is a way of maintaining ethnic heritage and defining cultural identity. Simultaneously, food culture is influenced by the availability of certain resources and living conditions. In my classroom, I began to explore ways of integrating food culture to engage students in a historical sensory 
experience. I did this by infusing food into our study of immigration and migration in the United States during the late nineteenth and early twentieth centuries. ${ }^{1}$

In this paper, I intend to include food, recipes, cookbooks, and restaurant menus as primary sources. These items allow history teachers to deepen student understanding of issues related to ethnic identity and assimilation. I developed a unit plan that focuses on immigration into New York City during the twentieth century and the purpose of this essay is to introduce the inclusion of food history in my lessons. I focus on the project students completed at the end of the unit where they engaged in three major tasks; first, using digital archives to create a timeline of events; second, doing a close analysis of one artifact in their timeline; and finally, doing an analysis of a food dish using a New York Public Library database of menus. I hope to encourage teachers to think of what we eat as part of our individual histories. By including food and its related ephemera as resources used in the classroom, history is more than words on a page or voices of the past; history is something we can eat too.

\section{An Apertif - Food Culture}

Luckily, history scholars who have tried to explain immigration and migration through images of food encourage this kind of exploration. Competing views of the melting pot and salad bowl theories provided some inspiration. I do not intend to ignore the justifications for these theories of assimilation, but there are other important questions for the purpose of this article. These images were used to describe the socialization of Americans and immigrant groups using food as a metaphor. I started to ask, what were Americans cooking? What is American food? When does an immigrant become American?

Hasia Diner argued that food has played a significant role in the development of political, economic, and social structures within communities. ${ }^{2}$ From agrarian communities based on hunting, gathering, and bartering to industrial societies in large urban neighborhoods, food has always driven the ways in which people interact. Gender roles often are attributed to food culture and preparation. Familial and celebratory practices revolve primarily around food and the dinner table. Food also

\footnotetext{
${ }^{1}$ This work was inspired by my experiences working with the New York Public Library and the National Endowment for the Humanities Grant program titled "Recipe for America: Immigration, Assimilation, and Food Culture." I participated in this teacher seminar during the summer of 2012. The seminar included lectures from history scholars that focused on subjects such as food culture, immigration, and identity development. We also spent time touring various immigrant communities around New York City and visiting museums, restaurants, and food carts to expand our study. At the end of the seminar, teachers created unit and lesson plans that integrated food into the teaching of history.
}

\footnotetext{
${ }^{2}$ Hasia Diner, Hungering for America: Italian, Irish, and Jewish Foodways in the Age of Migration (Boston: Haryard University Press, 2001).
} 
divides people: The poor do not eat the same items as the rich, and immigrant groups bring unique items and preparations from their own ethnic backgrounds. Food is politicized and manipulated by the government as seen in labor laws, production laws, the Food and Drug Administration, and even school lunches. Our personal tastes are products of experience. And as Diner noted, "for all human history people have contended with the stark reality that they must eat tó live."

Deciding to explore food culture and food identity at the turn of the twentieth century was an ideal fit because taste added a new element to a period of history rich in sights, smells, and visuals of bustling city streets and urban neighborhoods. The unit of study focused on immigrants arriving through Ellis Island and settling in Manhattan. The ethnic and racial makeup of Manhattan provides students the chance to explore diversity issues against the backdrop of industrialization and urbanization. As immigrants arrived, they usually sought out communities in which their own language and cultural needs could be met. One could walk down Orchard Street in the Lower East Side and find familiar faces, languages, crafts, and foods. And while beer, pickles, pretzels, cheeses, and kosher meats are commonplace in today's world, an exploration of their arrival and history allows students to evaluate the connection between food and ethnic identity.

The dill pickle is one of the most fascinating foods to study historically. And while I am specifically referring to pickled cucumbers, easily found in local markets and on pushcarts in the Lower East Side through the nineteenth century, I could also extend this discussion to the process of pickling. Many cultures in the world use pickling: kimchee in Korea, pickled jalapeños and carrots in Mexico, sauerkraut in Germany, and pickled herring in Eastern Europe. The process is historically and geographically situated and the need for pickling also relates to economic class, food sustainability, and living conditions. Depending on one's geographic location, pickling is a way to preserve meats and vegetables in order to last harsh winters where harvesting is impossible. Pickled goods are also fairly easy to prepare, sell, and trade within a community.

Students seemed to be fairly comfortable with the idea of pickling but could not believe we could take a historical, political, sociological, or economic stance on the effects of pickles. In one lesson, we focused on analyzing primary source documents from the late nineteenth century depicting pickle pushcarts and pickle stores. We sampled dill pickles and discussed the pushcart culture of immigrant communities in the Lower East Side. Jane Ziegelman, in her food history book 97 Orchard: An Edible History of Five Immigrant Families in One New York Tenement, explained that some "saw pickle-eating as a kind of compulsion" where "the undernourished child was drawn

${ }^{3}$ Ibid., 2 . 
to pickles the same way an adult was drawn to alcohol."." Ziegelman also noted that other concerns arose because Americans, mostly the wealthy from upper Manhattan, did not like the strong pungent smell of vinegar and feared germs from the shared barrel that required one to dip their arm inside to get a fresh pickle. During World War I, the push for temperance increased as anti-German sentiment spread into urban areas where bars and pubs served salty pickles alongside a cold glass of Bavarian beer. But pushcarts and street markets were a way of life. Despite challenges, they were simple to set up and a way for poor families to survive the hardships of starting over in the United States.

Because this was the first time that I included food as a part of the curriculum, I struggled to balance between the idea of teaching with food versus teaching about food. Students were definitely more interested in the lesson because they were eating and learning simultaneously. One day during the unit I served a buffet of options where students sampled foods from different cultures as we discussed processes of urbanization and assimilation for recent immigrants. Students made connections between pushcart culture and the elote (corn on the cob) or paleta (Popsicle) seller that is often waiting outside the gates of our school when the bell rings at the end of the day. After eating polenta, they exclaimed that it tasted like masa from tamales; we discussed the role corn has played in the cuisine of many cultures around the world because of its growth cycle and resilience in harsh conditions. Food issues from the past seemed to creep into my students' relationship with the present. This unit could have lasted longer than two days, but time constraints forced me to press on and begin working with students on the final project.

\section{Multiple Entrees - The Unit Project}

The unit project my students completed included three tasks: creating a digital timeline, examining an artifact, and analyzing a recipe. The goal of these three tasks were two-fold. First, I wanted to introduce students to online resources and visual media useful when studying history. Second, I wanted students to interact with digital platforms to create products that reflected the emerging technologies available today. Mystudents were given some introductory activities and directions on how to use digital galleries and choose effective key terms for searching as well as storing digital information. Each of the tasks did not directly reflect the inclusion of food history because other skills and content were being evaluated. However, inter-departmental connections can be made with culinary arts courses or nutrition courses to identify alternative assessment strategies that include multiple modalities and senses.

\footnotetext{
${ }^{4}$ Jane Ziegelman, 97 Orchard: An Edible History of Five Immigrant Families in One New York Tenement (New York: Harper, 2010), 150.
} 


\section{Digital Timeline}

In the first task, students explored digital collections of the New York Public Library (http://www.nypl.org). Having technology available in the classroom allows students to move beyond the walls of a school and into museums and libraries across the world. Other sites also provide digital field trips where students can walk down streets and view places being studied. For the purpose of this task, we focused on databases organized by the New York Public Library but found we had to branch out to include the Library of Congress (http://www.loc.gov/index.html) and the National Archives and Records Administration (http://www.archives.gov).

When students were introduced to the three digital collections, I did not provide detailed guidance as they searched for photographs, charts, graphs, and documents. I wanted to wander around the room, watching them use the websites and talk with their peers about the terms they were using to search. A negative effect of using search engines is that students struggle to narrow down results. Most students immediately did an image search, but I emphasized the need to track source information carefully that would be included in the timeline. After approximately fifteen minutes, I stopped the class and we debriefed their processes thus far. I guided them through some tasks regarding search terms, Boolean logic, and navigating databases. Instead of starting with the search bar, I showed students how to find tools and links built into the website that automatically narrow searches thematically, chronologically, or topically. Students also looked at their notes to determine what terms (e.g., nationality, geographic location, time period) would yield the desired results. After locating an appropriate image, the NYPL Digital Gallery lists alternate subjects and headings in order to find more documents. By reviewing the website's structure and organization, students were able to find information more quickly.

Students were responsible for collecting at least ten artifacts to include on their digital timeline. In small groups of two or three, students gathered images and began adding them to a website called Dipity (http://www.dipity.com) that supports the creation of interactive timelines. Each item that is added can include a title, date, description, picture, web link, and geographic location. The geographic location is a unique function. Not only can students view the timeline as a chronological chart or series of flashcards, they can also view a web-based world map that labels each one of the events they included on the timeline based on the location chosen. For a project on immigration, this was an important element so that students could see changes over time from a spatial and geographical perspective. I encouraged students to locate images that showed food in the home, community, or marketplace. They could see where different immigrant groups settled and developed their neighborhoods. The work that students did in completing this task was essential to the next part of the project where each student chose one artifact to study in more detail. 


\section{Examining an Artifact}

Students were required to choose one of the photographs they included in their digital timeline to evaluate in more detail. One graphic organizer (Figure 1) I use to examine visual artifacts utilizes a process called "See, Mean, Matter." This process requires students to (1) identify what they see by making observations about the details included in the picture; (2) infer the meaning behind some of their observations, including symbolism or connections to historical context; and (3) determine why this image matters or is significant to studying the time period. This process works particularly well when analyzing political cartoons because the three steps encourage students to break down visual media in order to infer historical importance.

\section{Figure I}

Image Analysis Tool

\begin{tabular}{|c|c|}
\hline $\begin{array}{c}\text { SEE } \\
\text { (What do I see?) }\end{array}$ & $\begin{array}{c}\text { MEAN } \\
\text { (What do the content and images } \\
\text { symbolize?) }\end{array}$ \\
\hline MATTER \\
(What is the creator's message, intent, or bias?)
\end{tabular}

For the purposes of this task, I added a step to the process that I called "voice." In addition to analyzing the observations students made based on what they saw in the photograph, I wanted them to use what they knew about the time period to construct a dialogue between the people within the picture. ${ }^{5}$ By placing themselves within the

'Edward T. O'Donnell, "Using Images to Teach History" (presentation, Recipe for America, New York, NY, August 1, 2012). Dr. O'Donnell is the author of several books regarding social science education and his lecture focused on the way teachers can use visual imagery in the classroom. His insightful practice of challenging students to develop fictional narratives based on photographs and paintings is what inspired me to add the element of "voice" to my graphic organizer. I appreciated his view of 
picture, students reflected upon the feelings and reactions of the people at that time. For example, I showed an image of a family arriving at Ellis Island. The father is not in the picture, the mother carries an infant while her other two children are at her side, and they are surrounded by several bags that appear to be their personal belongings. The title of the photograph indicates that the family is of Italian descent and had arrived to Ellis Island in the early 1900 s. Students practiced writing a dialogue this family might have had going through the arrival process into New York City. The children could have asked about the medical examinations, lunch options, or diversity of people. Sometimes students used anachronistic language when representing the thoughts of people in the pictures; however, the intention was to provide students with the ability to develop empathy and imagine what immigrants experienced arriving to the United States. When constructing the dialogue students used their notes and other documents read during the lessons to find key vocabulary to include. In the graphic organizer, I included space for students to cite their evidence by referencing materials that were studied in class or found during the time students independently conducted their research.

Another photograph we analyzed as a class depicted a different Italian family living in the Lower East Side. It appeared that two mothers were sitting with their infant children and young daughters while they shelled peanuts that were heaped on a table. This picture represented the way many immigrant families made a living by turning the home into a factory of sorts. Other images students found related to the home-as-factory theme were pictures of Orchard Street, which depicted a bustling community filled with street vendors. When adding the thoughts of the figures, students noted there were no sanitary regulations, no minimum wage, and no protection against child labor. They also noted the crowded tenements, harsh working conditions, and potentially long hours. They identified characteristics of urban life in Manhattan. Some of the documents students found within the database included restaurant menus and store fronts from the time period, which provided an important connection to the last task.

\section{Analyzing a Recipe}

For this part of the project, students participated in some important work being done by the New York Public Library. The NYPL Lab titled "What's on the menu?"

\footnotetext{
${ }^{5}($...continued $)$

studying history by emphasizing the need to "explore conflict," "humans as agents of change," and "the study of choices." Instead of viewing visual imagery as static and fixed in our historical memory, teachers and students can understand history as more fluid and transforming if we interpret information from multiple perspectives.
} 
is a digitized gallery of restaurant menus dating back to the $1850 \mathrm{~s}^{6}{ }^{6}$ The purpose of this project is to allow researchers to evaluate the types of dishes being served, the popularity of certain food items, the geographic location of food sales, a chronological account of menu preparation, an analysis of pricing, and the influences economic conditions have on eating habits. The website discusses the benefits of this collection and, to encourage historians to use the collection, offers up questions such as "Where were oysters served in nineteenth-century New York and how did varieties and cost change over time? When did apple pie first appear on the Library's menus? What about pizza? What was the price of a cup of coffee in 1907?"' This site is interactive and encourages visitors to join in the process of adding details from the menus to the searchable database.

The assignment my students completed included two parts. First, they added three menus they had researched to the database. We spent some time in the computer lab exploring the website and adding items to the digital library. Second, students chose one food item or dish to explore in more detail. They searched for information about the history of the food dish, including its ingredients, nation of origin, and cultural significance. I created a graphic organizer (Figure 2) to help students identify specific parts of the dish in order to make connections between the historical time period, the construction of the dish, and the diner who might enjoy it. I had hoped to challenge students to make the dish and bring it in as a way to share in the experience, but time and availability of ingredients prevented this from happening. Next year, I hope to work with our culinary arts teacher to discuss a project where our students can work together in making connections between food preparation and food history.

\footnotetext{
6"'What's on the menu?", New York Public Library, http://menus.nypl.org/, accessed September 2, 2015.
}

${ }^{7}$ Ibid., "About” page. 


\section{Figure 2 \\ Recipe as Primary Source}

Restaurant:

Location:

Year:

Recipe Title:

Price:

\begin{tabular}{|l|l|}
\hline Ingredients & \\
\hline Preparation & $\begin{array}{l}\text { How is the dish prepared? Are there variations from different } \\
\text { cultures? }\end{array}$ \\
\hline Brief history & $\begin{array}{l}\text { When was it first documented? Has it changed in preparation } \\
\text { or price over time? Where has it been served? Who might } \\
\text { have eaten this dish }\end{array}$ \\
\hline Why America? & $\begin{array}{l}\text { How does this recipe relate to the rise in immigration and } \\
\text { urbanization in the United States during the early 1900s? }\end{array}$ \\
\hline
\end{tabular}

\section{Just Desserts - Next Steps}

Do you have a favorite food memory? Is it a smell, a taste, or a texture that takes you back in time? When your senses are triggered, are you instantly transported to a place where you remember where you were, who made the dish, and whom you were with? I can remember the smell of sautéed garlic and olive oil lingering through the house on Sunday mornings. Each Sunday I visited a close family friend's home where marinara simmered on the stove, fresh parmesiano reggiano had been grated, and the pasta was cooking to a perfect al dente. We sat around the table with ten to fifteen people, ripped a piece of crusty bread, passed it to the next person, and talked about everything from school to politics and family affairs. I learned about my Nana and Papa's migration from Sicily to the United States where they opened a catering company serving Italian food. Smelling garlic and olive oil reminds me of family members, friends, and endless stories that help me explore my own personal history. Food memories are powerful. It is these memories that can inspire a new and invigorated interest in studying history.

This unit was the first time that I attempted to include food in my teaching. One thing I know about food is that it brings people together. Sharing conversations during meal time is just one way we communicate with our families, friends, and loved ones. 
Eating in my class is more than just part of the curriculum; it is part of the community. My morning classes are usually finishing their breakfast and my afternoon classes continue snacking throughout the day. I challenge myself to find ways to include food and food history regularly. Some of my students come back after having talked to family members about cherished dishes or after having sampled a new item. Eating is allowing my students to add a new element to their personal narratives. Each time we taste a familiar or even a new food we can be reminded of times past and open a gateway to studying history. 